\title{
Investigating and Comparing the Physicochemical, Microbial and Sensory Characteristics of Traditional and Pasteurized Siahmazgi Cheese
}

\author{
Zahra Katabehei Moradi ${ }^{1 *}$, Negin Nasiri ${ }^{1}$, Elma Tabari ${ }^{1,2}$, Hamed Kioumarsi $^{3}$ \\ ${ }^{1}$ Department of Agriculture and Food Industry, MehrAeen Higher Education Institute, Bandar-e Anzali, Guilan, Iran \\ ${ }^{2}$ Department of Exercise Physiology, Faculty of Education and Sport Science, University of Guilan, Rasht, Iran \\ ${ }^{3}$ Animal Science Research Department, Gilan Agricultural and Natural Resources Research and Education Center (AREEO), Rasht, Iran
}

\author{
DOI: $10.36348 /$ sjnhc.2019.v02i11.002 \\ | Received: 29.10.2019 | Accepted: 05.11.2019| Published: 12.11 .2019 \\ *Corresponding author: Zahra Katabehei Moradi
}

\section{Abstract}

Healthy food production is the main priority of food technology and dairy products which plays an important role in the household food basket. Traditional dairy products take a large part in the market and sometimes are causing transmission of various diseases to humans, particularly in the cheese market. Siahmazgi cheese is a type of traditional cheese, produced from raw milk in the north of Iran, and is getting increasingly popular. In this research, physicochemical, microbial and sensory characteristics of five samples of bought traditional cheese and five samples of manufactured pasteurized cheese are studied on days 0,30 , and 60 . The result of the physicochemical survey shows the solids content, $\mathrm{pH}$, and fat contents of traditional and pasteurized cheese samples decreased over 60 days, but the difference was not always statistically significant. On the other hand, the protein and salt content of traditional and pasteurized cheeses significantly increased over 60 days $(\mathrm{p}<0.05)$. The protein and salt content were higher in traditional samples. The results also revealed that pasteurization eliminates pathogens from cheese whereas most of the traditional Siahmazgi cheeses were infected by Coliform, Escherichia coli, yeast-mold, and staphylococcus. There was not observed salmonella infection in any samples of traditional Siahmazgi cheeses. Sensory evaluation between pasteurized and traditional Siahmazgi cheese shows that only texture has significantly changed over 60 days and the other sensory features were the same.

Keywords: Cheese, Siahmazgi, physicochemical, microbial, sensory.

Copyright @ 2019: This is an open-access article distributed under the terms of the Creative Commons Attribution license which permits unrestricted use, distribution, and reproduction in any medium for non-commercial use (NonCommercial, or CC-BY-NC) provided the original author and source are credited.

\section{INTRODUCTION}

Milk and dairy products are adequate foods and are important sources of mineral nutrients for most human beings. On the other hand, dairy products are contaminated with dangerous illnesses such as meningitis and infection [1]. The earliest evidence of cheese-making dates back to 5,500 $\mathrm{BCE}$ and it is the oldest way for maintaining milk. From the past human have noted that whenever the milk is clot and its serum is separated, the resulting clot is removable and maintained [2]. The main part of the produced milk in Iran is transferred to traditional cheese production. Although traditional cheeses are preferred for their sensory characteristics, there are always risks of contamination to a variety of microbes [9]. The bacterial population in milk can have positive and negative effects on the cheese, its positive role is the effect of these bacteria as probiotics in the human body, on the other hand, some of these bacteria can cause spoilage (Bacillus and Clostridium), and some bacteria such as Salmonella and Escherichia coli cause food poisoning in humans [3]. Although a large population of pathogenic bacteria is killed during the process of making cheese, due to the resistance of some of the species, there are still some pathogenic bacteria that could be found in the cheese that causes infections [1]. Cheeses made with raw milk are more favorable because pasteurization can also kill good bacteria that make the nuances of flavor in cheese but it is also less safe [4]. Consumers in French, select unpasteurized cheese, while Norwegian consumers choose pasteurized cheese and cheeses made with raw milk cannot be sold in the US unless they have been aged for at least 60 days at a temperature no less than $35^{\circ} \mathrm{F}$ [5].

Siahmazgi cheese, a traditional cheese in Guilan province, is produced in the Siahmazgi County, in the past; the cheese was produced from sheep's milk, 
but today is mainly produced in Zanjan province and from cow's milk. The operation of the ripening of the Siahmazgi cheeses like other traditional cheeses prepared from raw milk is done by milk bacteria during the storage time of cheese [6]. Cheese in terms of fat percentage is divided into high fat, fat, semi-fat, low-fat and free fat. Cheese is divided in terms of solids content to very hard, hard, semi-hard and soft (the International cheese Codex). The Siahmazgi cheese is very hard with medium fat [7]. In general, Siahmazgi cheeses are important in terms of its quality and its economical values. This study aims to investigate and compare the physicochemical, microbial and sensory properties of traditional and pasteurized Siahmazgi cheeses.

\section{METHOD}

In this study, 5 samples of traditional Siahmazgi cheese were purchased and 5 samples of the pasteurized Siahmazgi cheese were produced. Traditional and pasteurized samples were packed in vacuum packaging and stored in a refrigerator at a temperature of $6^{\circ} \mathrm{C}$, during the experiment. The samples were evaluated by day Zero, 30 and 60 of physicochemical, microbial assessment and 60 days. The sensory evaluation was sown after day 60 .

For the production of pasteurized cheeses, the whole milk was pasteurized and homogenized, then at $30 \mathrm{C}^{\circ}$ temperature the starter was added, and after half an hour at $30 \mathrm{C}^{\circ}$ temperature, the rennet was added. After forming the clot until the temperature will be increased to $45 \mathrm{C}^{\circ}$, then the whey will be removed and the remained will be pouring the molds and after reaching the appropriate $\mathrm{pH}$ will be placed in saltwater or dry salt. To produce traditional Siahmazgi cheeses, it is not necessary to pasteurized milk or adds the starter.
In physicochemical tests, $\mathrm{pH}$ was determined using a calibrated $\mathrm{pH}$ meter, protein measured using Kjeldahl method, salt content by the Mohr method, fat content by Gerber method and total solids content measured using an oven. In the microbial tests, treatments were evaluated for coliform, Escherichia coli, yeast and mold, Staphylococcus aureus, and Salmonella spp. In the physicochemical tests, treatments were evaluated for protein, humidity, salt, fat, and $\mathrm{pH}$. All physicochemical and microbial tests were performed using the standard methods [8]. In the days 60, traditional and pasteurized Siahmazgi cheeses were evaluated by professional panels for measuring sensory characteristics. Sensory analyses were included measuring the color, aroma, taste, and texture. Data were statically analyzed using a one-way analysis of variance (ANOVA) and mean comparisons were done by Duncan method through SPSS version 16.

\section{RESULTS AND DISCUSSION Evaluation of Protein}

The physicochemical evaluation of pasteurized and traditional Siahmazgi cheese is presented in Table1. The results of the experiments showed a significant increase in the protein of traditional and pasteurized cheeses during the 60 days. Traditional Siahmazgi cheese had higher protein content. During cheese ripening, the solids' content of samples decreased and as a result increasing cheese protein is expected. Mortazavi et al., [9], Farahani et al., [10], and Mirzae and Aligholi Nezhad [11], which had been studied Kurdish cheese, Siahmazgi and Lighvan cheeses, observed the same results. Sarbazi et al., [4], with the survey of pasteurized and non-pasteurized Kope cheese, found that the protein content of non-pasteurized cheese is higher than pasteurized cheeses, concluded that this could be due to the effects of pasteurization on the dry matter as well as protein.

Table-1: Physico-chemical evaluation of pasteurized and traditional Siahmazgi cheese on days 0, 30, and 60

\begin{tabular}{|c|c|c|c|c|}
\hline Properties & Samples & Day 0 & Day 30 & Day 60 \\
\hline Protein & Pasteurized & $19.40 \pm 0.843$ & $21.04 \pm 1.120$ & $23.06 \pm 0.764$ \\
\cline { 2 - 5 } & Traditional & $21.52 \pm 1.301$ & $23.53 \pm 1.401$ & $25.66 \pm 1.148$ \\
\hline \multirow{2}{*}{ Humidity } & Pasteurized & $40.02 \pm 1.480$ & $38.70 \pm 1.173$ & $37.48 \pm 0.834$ \\
\cline { 2 - 5 } & Traditional & $39.98 \pm 1.681$ & $38.78 \pm 1.723$ & $37.04 \pm 1.722$ \\
\hline \multirow{2}{*}{ Salt } & Pasteurized & $2.74 \pm 0.15$ & $3.38 \pm 0.15$ & $3.38 \pm 0.15$ \\
\cline { 2 - 5 } & Traditional & $4.62 \pm 0.5$ & $4.86 \pm 0.4$ & $5.16 \pm 0.4$ \\
\hline \multirow{2}{*}{ Fat } & Pasteurized & $28.7 \pm 1.643$ & $27 \pm 1.767$ & $25.10 \pm 2.21$ \\
\cline { 2 - 5 } & Traditional & $26.8 \pm 2.7$ & $26 \pm 2.9$ & $24.9 \pm 2.60$ \\
\hline \multirow{2}{*}{$\mathrm{pH}$} & Pasteurized & $5.16 \pm 0.29$ & $5.01 \pm 0.13$ & $4.84 \pm 0.16$ \\
\cline { 2 - 5 } & Traditional & $5.06 \pm 0.2$ & $4.88 \pm 0.25$ & $4.80 \pm 0.27$ \\
\hline
\end{tabular}

\section{Evaluation of Humidity}

The results of the experiment showed a gradual reduction in solids content and dry matter increase, however, this reduction was not significant. Farahani et al., [10], by examining the dry matter of Siahmazgi cheese samples within 6 months, concluded that the dry matter of samples was not reduced. Mirzae and Aliqholi Nezhad [11], also observed the same results.

\section{Evaluation of Salt}

The salt increased during process of making cheese, in traditional and pasteurized cheeses, which are caused by reducing solids content and increasing dry 
matter of cheese, the results were in line with the foundings of Mirza Alizadeh et al., [6], Farahani et al., [10], Mortazavi et al., [9], Cetinkaya and Soyutemiz [12], and Psoni [13].

\section{Evaluation of Fat}

Based on the results of the experiments, fat samples of traditional and pasteurized cheeses decreased during the test period, the results of this reduction were not significant. Lipolysis in the vacuum packaging is the reason for the reduction of cheese fat. Sarbazi et al., [4] had a similar opinion about cheese packaging jars in plastic containers.

\section{Evaluation of $\mathbf{p H}$}

The results of the research showed that the $\mathrm{pH}$ was reduced in traditional and pasteurized cheese samples. A slight reduction in $\mathrm{pH}$ can be observed by the effect of temperature after the formation of clots, which causes the changes in the lactic acid and bacteria in pasteurized cheeses. In traditional cheeses, high salt rates prevent $\mathrm{pH}$ loss. Psoni et al. [13], achieved a similar result.

\section{Evaluation of Coliform}

The microbial evaluation of pasteurized and traditional Siahmazgi cheese is presented in Table-2. The samples of pasteurized cheese were lacking coliform, but all traditional Siahmazgi cheeses showed a general form of infection. Mirza Alizadeh et al., [6], stated that the use of raw milk is considered the most important reason for the contamination of traditional cheeses. Loghmanifar et al., [14], mentioned that the reason for the intense contamination of traditional Siahmazgi was used to use raw milk, non-use of lactic culture and maintenance of cheese in conditions of poor temperature. The high microbial count in the soft cheeses in Jordan is suitable due to poor health conditions, inadequate cooling equipment and nonapplication of thermal conditions [15]. Mortazavi et al., [9], revealed that the pasteurized cheese shows no evidence of infection to coliform, they concluded that this is due to the high concentration of salt and low $\mathrm{pH}$ of the pasteurized cheese.

Table-2: Microbial evaluation of pasteurized and traditional Siahmazgi cheese on days 0, 30, and 60

\begin{tabular}{|c|c|c|c|c|}
\hline Property & Samples & Day 0 & Day 30 & Day 60 \\
\hline \multirow[t]{2}{*}{ Coliform } & Pasteurized & $\% 0$ & $\% 0$ & $\% 0$ \\
\hline & Traditional & $\begin{array}{c}\% \\
100\end{array}$ & $\% 100$ & $\% 100$ \\
\hline \multirow[t]{2}{*}{ Escherichia coli } & Pasteurized & $\% 0$ & $\% 0$ & $\% 0$ \\
\hline & Traditional & $\begin{array}{c}\% \% \\
100\end{array}$ & $\% 60$ & $\% 60$ \\
\hline \multirow[t]{2}{*}{ Yeast and mold } & Pasteurized & $\% 80$ & $\% 80$ & $\% 80$ \\
\hline & Traditional & $\begin{array}{c}\% \\
100\end{array}$ & $\% 100$ & $\% 100$ \\
\hline \multirow[t]{2}{*}{ Staphylococcus aureus } & Pasteurized & $\% 0$ & $\% 0$ & $\% 0$ \\
\hline & Traditional & $\% 80$ & $\% 80$ & $\% 80$ \\
\hline \multirow[t]{2}{*}{ Salmonella } & Pasteurized & $\% 0$ & $\% 0$ & $\% 0$ \\
\hline & Traditional & $\% 0$ & $\% 0$ & $\% 0$ \\
\hline
\end{tabular}

\section{Evaluation of Escherichia Coli}

The results of the experiments showed that none of the pasteurized cheese samples were contaminated with Escherichia coli while in all samples of traditional cheese was infected. At the end of the storage period, only $40 \%$ of the traditional cheeses were not infected with Escherichia coli. This can be because lowering the $\mathrm{pH}$ until the end of the period was not so tangible to be able to fully eliminate the Escherichia coli. $50 \%$ of the traditional cheeses in the city of Maragheh were contaminated with Escherichia coli. The possibility of contaminated cheeses with E. coli has a large correlation with the frequency of contamination. The presence of Escherichia coli in samples can also increase the likelihood of other intestinal pathogens [1]. There were Escherichia coli in cheese from Southeastern Serbia. E. coli arrived in cheese by unpasteurized milk [16]. Simsek and Tuncer, [17] had also observed the same results in their studies.
Evaluation of Molds and Yeasts

All traditional cheese samples were contaminated with mold and yeast, which over time, the amount of infection was increased. Amongst the 5 samples of pasteurized cheeses, just one sample was contaminated with molds and yeasts. The results could be justified due to $\mathrm{pH}$ reduction in the pasteurized cheeses, Mirza Alizadeh et al., [6], in a study on traditional cheese, observed that the amount of mold and yeast were higher than other bacteria. Mortazavi et al., [9] had also observed the same results in their studies on traditional Kurdish cheese, a statistically significant increase in mold and yeast was observed during the process of making cheese. They stated that the reduction of lactose and lactic acid increases during cheese ripening provides conditions for the growth of mold and yeast. The findings of the current study were in line with the study conducted by Haddad and Yamani [15] who observed a higher number of molds and yeasts in traditional cheeses in Jordan. 


\section{Evaluation of Staphylococcus Aureus}

The results of the study showed that the pasteurized cheese had no evidence of infection by Staphylococcus aureus, while the traditional cheeses were infected up to $80 \%$. Mirza Alizadeh et al., [6], evaluated the traditional cheese samples in Zanjan province, it was found that reducing $\mathrm{pH}$ to 4.2 caused the destruction of bacteria, including Staphylococcus aureus, in these cheeses. Partovi [7] also, mentioned a high rate of infection with Staphylococcus aureus in traditional Siahmazgi cheeses due to the use of raw milk and failure to comply with safety standards. Loghmanifar et al., [14] studied the Siahmazgi cheese samples in Rasht and found the $95 \%$ of the samples were infected with Staphylococcus aureus.

\section{Survey of Salmonella Changes}

In none of the samples of traditional and pasteurized Siahmazgi cheeses tested, Salmonella was found. Mirza Alizadeh et al., [6] in his survey mentioned that no salmonella was observed in traditional Siahmazgi samples. The findings of the current study were in line with the study conducted by Dimitrovska et al., [18] in the Republic of Macedonia and Loghmanifar et al., [14], in Iran. Mortazavi et al., [9], studied the traditional cheese samples and mentioned that the salmonella population was zero in the day 60 , which is due to increasing water activity, reducing acidity and high salt concentration in this cheeses.

\section{Sensory Evaluation}

The sensory characteristics of pasteurized and traditional Siahmazgi cheese are presented in Figure-1. Sensory analyses are the best methods to evaluate the color, aroma, taste, and texture of cheese. However, the traditional cheese received a higher score regarding the texture, which could be due to the presence of natural bacteria in unpasteurized milk which boosts a better texture in traditional cheese. It has been proven that the heat treatment of milk changes its properties. Also, many of these changes depend on the intensity of the thermal treatment $[19,20]$. No significant differences were observed in other sensory factors.

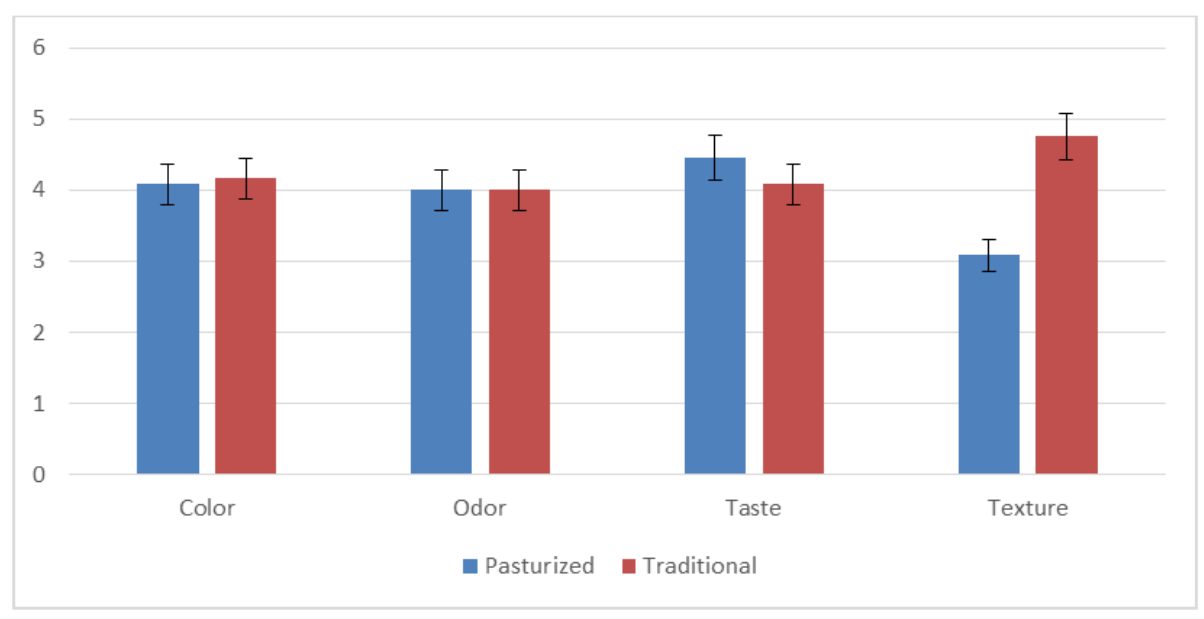

Fig-1: The sensory characteristics of pasteurized and traditional Siahmazgi cheese

\section{CONCLUSION}

Although both pasteurized and traditional cheese had no evidence of contamination to salmonella, microbial contamination (Coliform, Escherichia coli, yeast and mold, and Staphylococcus aureus) was higher in traditional cheese than standard allowable. The pollution was reduced at the end of the period but was not eliminated. Thus, pasteurized cheese is more recommendable unless there could be a way to reduce contamination in traditional cheese. Regarding the sensory test except for the texture, the rest of the factors did not change during the experiment. Thus, both methods are recommendable in this regard. However, the selection and application of appropriate microbial cultures that can improve the cheese sensory characteristic are recommendable.

\section{ACKNOWLEDGMENTS}

The support by the MehrAeen Higher Education Institute is gratefully acknowledged. The authors also would like to thanks the Shirin Cheshmeh Guilan for all the facilities provided.

\section{REFERENCES}

1. Vaziri, S., \& Naghshbandi, N. (2011). Evaluation of contamination of local cheeses of Lighvan Tabriz with coliform and Escherichia coli. Iranian Journal of Medical Microbiology, 4(5), 23-28.

2. Leksir, C., Boudalia, S., Moujahed, N., \& Chemmam, M. (2019). Traditional dairy products in Algeria: case of Klila cheese. Journal of Ethnic Foods, 6(7), 1-6.

3. Ajazi, F. C., K. Kurteshi, M. A. Ehrmann, R. Gecaj, M. Ismajli, B. Berisha., \& Vehapi, I. (2018). Microbiological study of traditional cheese produced in Rugova region of Kosovo. Bulgarian Journal of Agricultural Science, 24(2), 321-325. 
4. Sarbazi, M., Hesari, J., Azadmard, S., \& Damirchi, S. R. (2014). Effect of pasteurization and packaging on the physicochemical and sensory properties of Kope cheese. Journal of Food Research, 24(4), 507-517.

5. Almli, V. L., Næs, T., Enderli, G., Sulmont-Rossé, C., Issanchou, S., \& Hersleth, M. (2011) Consumers' acceptance of innovations in traditional cheese. A comparative study in France and Norway. Appetite, 57(1), 110-120.

6. Mirza-Alizadeh, A., Mashayekh, M., Banikhademi, S., Mohammdi, M., Haj Heidary, R., Mousavi, M. M., \& Pilevar, Z. (2019). Microbial and Chemical Parameters of Traditional Siahmazgi Cheese produced in Zanjan Province, Iran.

7. Partovi, R., Gandomi, H., Akhondzadeh Basti, A., Noori, N., Nikbakht-Borujeni, G., \& Kargozari, M. (2015). Microbiological and Chemical Properties of Siahmazgi Cheese, an Iranian Artisanal Cheese: Isolation and Identification of Dominant Lactic Acid Bacteria. Journal of Food Processing and Preservation, 39(6), 871-880.

8. A.O.A.C. (1990) Official Methods of Analysis. 15th Edition, Association of Official Analytical Chemist, Washington DC.

9. Mortazavi, E., Milani, A., \& Moeinfar, M. (2013). Evaluation of microbial population profiles of traditional Kurdish cheeses and their relationship with physicochemical and sensory characteristics of the product during the ripening period. Iranian Food Science and Technology Research, 11(2), 140-151.

10. Farahani, G., Ezzatpanag, H., \& Abbasi, S. (2014). Characterization of Siahmazgi cheese, an Iranian ewe's milk varety: assessment of physicochemical, textural and rheological specifications during ripening. $L W T$ - Food Science and Technology, 58(2), 335-342.

11. Mirzae, H., \& Aligholi Nezhad, A. (2011). A study on the chemical characteristics changes throughout the manufacture and ripening of Lighvan cheese. Veterinary Journal of Islamic Azad University, 5(2), 1161-1168.
12. Cetinkaya, F., \& Soyutemiz, G. E. (2006). Microbial and chemical changes throughout the manufacture and ripening of Kashar: a traditionai Turkish cheese The Turkish Journal of Veterinary and Animal Sciences, 30(2), 347-404.

13. Psoni, L., Tzanetakis, N., \& Litopoulou-Tzanetaki, E. (2003). Microbiological characteristics of batzos, a traditional Greek cheese from raw goa'ts milk. Food Microbiogy, 20(2), 575-582.

14. Loghmanifar, S., Loghmanifar, S., \& Rozbehnasiraei, L. (2014). Study and identification of microbial flora of Siahmezgi marketed in Rasht. Second National Conference on Applied Research in Agricultural Sciences, Tehran, Iran, 1-3.

15. Haddad, M. A., \& Yamani, M. I. (2017). Microbiological Quality of Soft White Cheese Produced Traditionally in Jordan. Journal of Food Processing and Technology, 8(12), 1-6.

16. Mladenovic, K. G., Muruzovic, M. Z., Petrovic, T. Z., \& Comic, L. R. (2018). Escherichia coli identification and isolation from traditional cheese produced in Southeasern Serbia. Journal of Food Safety, 38(4), 12-24.

17. Simsek, B., \& Tuncer, Y. (2018). Some Properties of Fresh and Ripened Traditional Akcakatik Cheese. Korean Journal for Food Science of Animal Resources, 38(1), 110-122.

18. Dimitrovska, G., Srbinovska, S., Presilski, S., Manevska, V., Kochoski, L. J., \& Josheska, E. (2016). Traditional production and chemical composition of "Bieno cheese" in the republic of Macedonia. Journal of Faculty of Food Engineering, 15(1), 2016, 55-60.

19. Schreiber, R., \& Hinrichs, J. (2000). Rennet coagulation of heated milk concentrates. Le Lait, 80(1), 33-42.

20. Valente, N. I. P., Rudnitskaya, A., Oliveira, J. A. B. P., Gaspar, E. M. M., \& Gomes, M. T. S. R. (2018). Cheeses made from raw and pasteurized cow's milk analysed by an electronic nose and an electronic tongue. Sensors, 18(8), 2415. 